Austria-are lost, according to the report. If tropical forests continue to be cleared at the current rate, at least 556 million acres ( 225 million hectares) will be destroyed by the year 2000; if destruction of tropical rain-forests continues unabated, an estimated $10 \%$ to $20 \%$ of the Earth's plant and animal life will be gone by the year 2000 .

The report says that 'the real causes of deforestation are poverty, skewed land-distribution, and low agricultural productivity.' At least $30 \%$ of the investment proposed in the report would be agriculture-related.

Tropical Forests: $A$ Call for Action focuses on translating known solutions and strategies into a five-years' programme of accelerated action that will lay the groundwork for longer-term investment. Examples of successful projects illustrate the range of solutions available. Based on these success stories, and the lessons learned from past failures, high-priority areas for investment and action are proposed. Major policy-issues and constraints that need to be addressed to carry out the programme are specified.

The action programme addresses five issues: fuel-wood and agro-forestry; land-use on upland watersheds; forest management for industrial uses; conservation of tropical forest ecosystems; and strengthening institutions for research, training, and extension.

Among the report's recommendations are:

- Expenditures of \$8 thousand millions (US) over five years, half of which would need to be mobilized by development assistance agencies and international lending institutions, with the remainder coming directly from the private sector and the governments of tropical countries.
- Revision of specified government policies that encourage exploitation, depletion, or waste, of forest resources.

- Planning of development projects in transportation and irrigation to avoid wasting or destroying forest resources, jeopardizing forest conservation areas, or making accessible to settlers those forest areas that are unsuited for sustained agriculture.

- Establishment of policies that encourage local participation in rural tree-planting programmes and natural forest management.

- More extension work with women, who play an important role in the use and management of trees, and with the 5,000 nongovernmental organizations involved in forestry world-wide.

Tropical Forests: A Call for Action has been presented to the World Commission on Environment and Development (at its 28 October 1985 meeting in São Paulo, Brazil) and to development assistance agencies from around the world at a meeting in November 1985 in The Hague, Netherlands. The report contributes to the efforts of the Food and Agriculture Organization of the United Nations, which declared 1985 the 'International Year of the Forest.' It is available for $\$ 12.50$ from WRI Publications, P.O. Box 620 , Holmes, Pennsylvania 19043, USA.

F. William Burley, Project Director
World Resources Institute
1735 New York Avenue, NW
Washington
$D C$, USA.

\title{
The International Society for Tropical Ecology
}

The International Society for Tropical Ecology (ISTE) has now completed publication of the 25th Volume (2 issues per volume) of its journal, Tropical Ecology. The Journal publishes research papers and reviews on all aspects of Ecology, from throughout the tropics and subtropics, written in English, French, Portuguese, or Spanish, with their abstracts in all the four languages. The Journal matches other international publications in its scientific content, and is printed on glazed art paper. At present, it usually takes six months for a paper to get published in the Tropical Ecology from the date of its acceptance.

The journal is supplied free to all members of ISTE, and is sent by surface mail. Despite heavy publication and other costs, the Society continues to maintain the following annual rates of subscription: Individuals, U.S. Dollars 10 in Developing countries or 20 in Developed countries; Institutions, U.S. Dollars 40 (anywhere).

All persons and institutions interested in tropical ecology are invited to join the Society, and to submit papers for due consideration for publication. Please address enquiries to:
International Society for Tropical Ecology, c/o Department of Botany, Banaras Hindu University, Varanasi 221005, India-for matters regarding membership, to Professor R.S. Ambasht; for subscriptions, to Professor D.N. Rao; and manuscripts or other matters pertaining to publication, to Dr K.P. Singh.

Currently the Editorial Board of Tropical Ecology consists of Professor J.S. Singh (Chief Editor), Dr K.P. Singh (Executive Editor), Professor J.S. Singh \& Professor Peter Murphy (English Language Editors), Dr V.M. MeherHomji (French Language Editor), Dr J.Tundisi (Portuguese Language Editor), Dr S. Guevara (Spanish Language Editor), and Professor D.N. Rao \& Dr K.C. Misra (Ex-officio Members).

R.S. AMBASHT, Joint Secretary, ISTE
Centre of Advanced Study
Department of Botany
Banaras Hindu University
Varanasi 221005
India.

\section{Conservation Research Opportunities at the Wau Ecology Institute, Papua New Guinea}

The diverse forests and high mountains of Papua New Guinea offer great opportunities for studies of tropical ecology. Few areas have a greater diversity of species. In the current context of efforts to understand and perpetuate tropical ecosystems, it is important to investigate those of New Guinea, where $70 \%$ of the forests are still intact, and natural systems can be studied from sea-level to high elevations.
The Wau Ecology Institute (WEI) is situated advantageously among mountains not far from the north-east coast of the great island (Fig. 1), with access to many altitudes and environments. Indeed the area may be one of the best anywhere for the study of tropical ecology, because of the variety of environments and the lack of a cool or dry season. At $1,200 \mathrm{~m}$ the mean annual rainfall is $1900 \mathrm{~mm}$, while the mean temperature is $22^{\circ} \mathrm{C}$. 


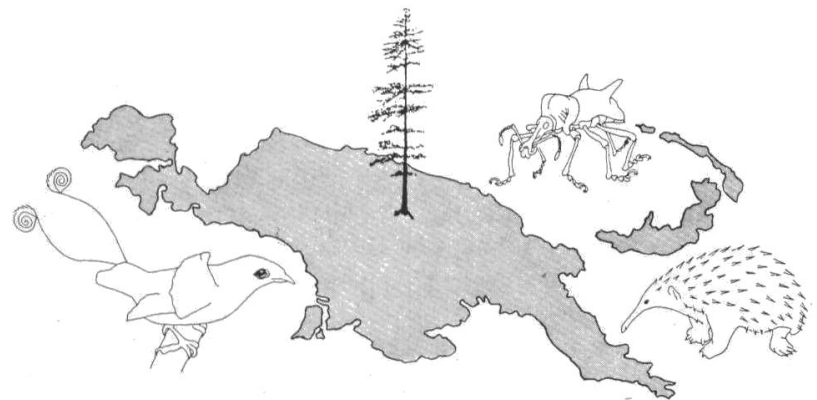

FIG. 1. The heraldic sign of the Wau Ecology Institute (WEI). On the left is a bird-of-paradise and on the right are characteristic animals of New Guinea. The main island includes 'West Irian' and, after Greenland, is the world's largest non-continent island, being nearly $800,000 \mathrm{sq} . \mathrm{km}$ in total area.

WEI is located on the lower slopes on Mount Kaindi $(2,362 \mathrm{~m})$, at $1,200 \mathrm{~m}$ in Wau Valley $\left(7^{\circ} \mathrm{S} ; 146^{\circ} \mathrm{E}\right), 150 \mathrm{~km}$ by road from the port city of Lae. A branch station is located in Nothofagus forest on the summit of Mt Kaindi, and is accessible by road. Several field-camps have been established on the slopes of Mt Missim $(2,900 \mathrm{~m})$, which spans the north side of Wau Valley.

The WEI grounds encompass 80 ha and include a large arboretum of native plants, remnant forest, coffee and experimental gardens, rhododendron and vegetable gardens, and a small zoo (Fig. 2). There is a laboratory with library, plant and animal reference collections, dry rooms with basic equipment and some working space, and a dark room. There are also a hostel, some guest houses, and vehicles for rent or sharing. The branch station on $\mathrm{Mt}$ Kaindi has bunks, a kitchen, electrictity, and a small laboratory. Extensive meteorological data are regularly collected there.

WEI is located near the interface between Araucaria and 'oak' (Lithocarpus-Castanopsis) forest. Higher elevations are dominated by Elaeocarpus (1,700-2,100 m), Nothofagus $(2,100-2,500 \mathrm{~m})$, and conifers (mainly Podocarpaceae, $2,500-3,000 \mathrm{~m}$ ). Areas above $3,200 \mathrm{~m}$ have a mosaic or Danthonia-Deschampsia grassland, forest, or tundra. Expanses of Imperata, Rhododendron, Vaccinium, Banksia, Cycas, etc., occur from 1,100-1,700 m east of Wau.

The Wau Area is rich in rhododendrons, with over 25 species. Towards the sea there is easy access to hill-, lowland-, and swamp-forests, as well as to sago and mangrove swamps, lowland savanna, and grassland. Several hundred species of birds, including 14 species of birds-of-paradise and many parrots, as well as about 65 species of mammals

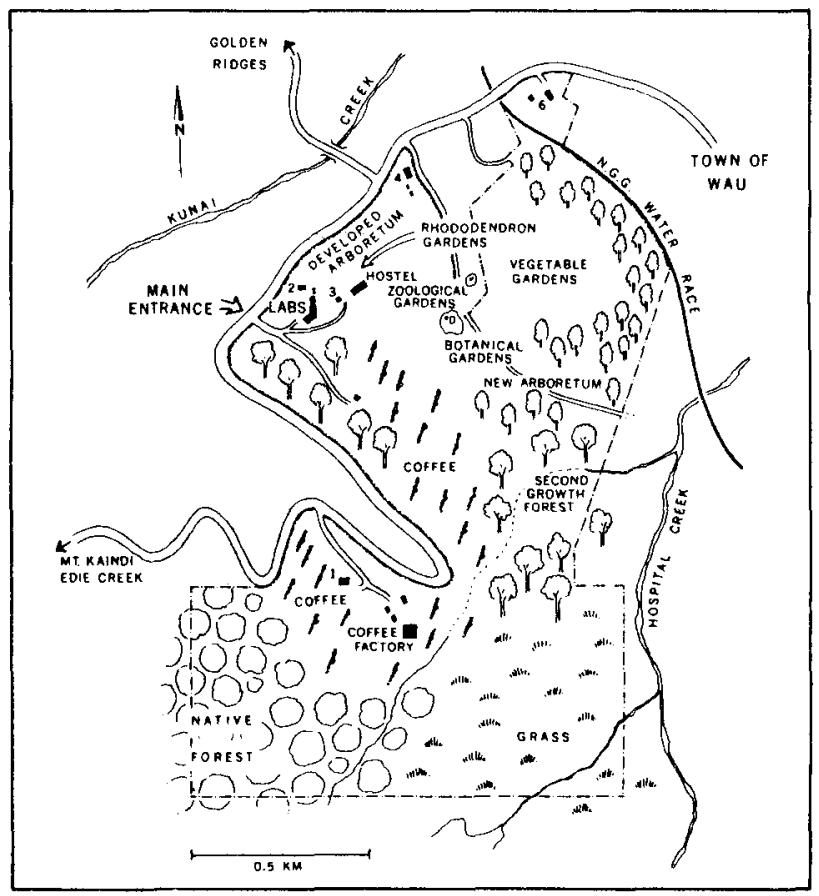

FIG. 2. Sketch-map showing layout of main features of the Wau Ecology Institute, Papua New Guinea.

and many reptiles, amphibians, and of course insects, occur nearby.

WEI is engaged in project work concerning conservation and medicinal plants. It is a non-governmental, non-profitmaking, cooperative, that can assist in preparation of requests for grants and in providing information, but cannot provide financial support. WEI has published handbooks on frogs, beetles, birds, rodents, reptiles, and subsistence-agriculture improvement, as well as on the local environment. Publications and information are available from WEI, and further publications are in preparation.

Friedhelm Goeltenboth, Acting Director Wau Ecology Institute PO Box 77

Wau

Morobe Province

Papua New Guinea.

\section{Food Safety: A World-wide Public Health Problem}

Despite the advances of modern technology, keeping food safe for humans remains a world-wide public health problem in both developed and developing countries. Illness resulting from contaminated food is a leading cause of sickness and death especially in the less-developed world, and affects untold millions in all countries.

While few precise figures are available, WHO estimates that only a fraction of food-borne disease is currently recognized and reported throughout the world. In lessdeveloped countries, the ratio between actual and reported cases may be as high as $100: 1$, while in industrialized countries the food-connected health incidents that are reported still probably represent far less than $10 \%$ of the actual total.

\section{Acute Diarrhoea a Killer}

Contaminated food is responsible for a high proportion of diarrhoeal and other infectious diseases, particularly in the less-developed world. WHO estimates that in 1984 there were about 1,000 million episodes of acute diarrhoea among children under five years of age in Africa, Asia (excluding China), and Latin America; the disease proved fatal for nearly five million cases.

Diarrhoea is a significant health-problem for the adult population too-especially for those who travel. Of some 2,600 million people who travel each year for business, pleasure, or other reasons, WHO estimates that between $20 \%$ and $50 \%$ suffer from diarrhoea, much of it caused by contaminated food or water. 